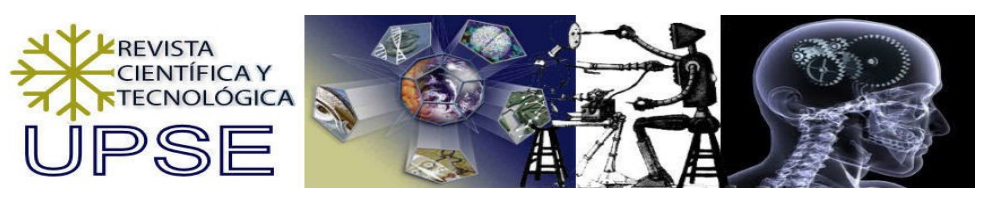

\title{
LA INVESTIGACIÓN CIENTÍFICA DEL ECUADOR EN LA ANTÁRTIDA Y SU CONSOLIDACIÓN $2005-2008$
}

\author{
Hernán Moreano1
}

\author{
1 Instituto de Investigación Científica y Desarrollo Tecnológico \\ Universidad Estatal Península de Santa Elena \\ Campus Universitario Vía Santa Elena - La Libertad \\ La Libertad - Ecuador \\ hmoreano@gye.satnet.net
}

* Recordar que además del Director del proyecto, los demás investigadores involucrados en el proyecto(docentes,
estudiantes) son coautores del Artículo y también deben registrarse en este apartado.

\section{Resumen}

La necesidad de que el Ecuador fortalezca su protagonismo en la ciencia antártica y el cumplimiento del mandato del Congreso Nacional de 1987 fueron razones suficientes para crear el Instituto Antártico Ecuatoriano y replantear la gestión previa conducida por el Programa Antártico. La nueva visión se tradujo por un lado en un mayor involucramiento de la academia para potenciar e innovar la actividad y calidad científica del Ecuador y por otro, se mantuvo la relación con la Fuerza Naval para atender lo logístico y operativo. Los resultados se traducen en una excelente producción científica y en una activa participación en todas las instancias del Sistema del Tratado Antártico y en aquellas relacionadas al Comité Científico de Investigación sobre la Antártida.

Palabras clave: Ecuador Antártico, Continente Austral

\begin{abstract}
The need to strength Ecuador's leadership on Antarctic Science and the Act of the National Congress in 1987 were good reasons to create the Ecuadorian Antarctic Institute and refocus the previous management under the Ecuadorian Antarctic Program. The new vision considers a better involvement of Academia to strength and innovate activities and quality of science, keeping the support of the Navy for logistic and operational matters. Results show an excellent scientific production and an active participation within both: the Antarctic Treaty System and the Scientific Committee on Antarctic Research.
\end{abstract}

Key Words: Ecuador Antartico. Southern Continent 


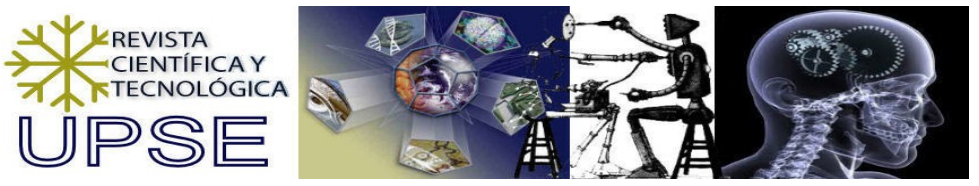

\section{1.- Introducción:}

La Antártida es una reserva natural, zona de paz y ciencia que la administran las Partes Consultivas en base a una institucionalidad legal conformada por el Tratado, las Convenciones y el Protocolo de Madrid, que en conjunto aseguran: que el principio de cooperación sea el que oriente la gestión científica de cada una de las Partes, que el aporte de la investigación permita armar el rompecabezas de la historia del clima del Planeta Tierra y que las actividades científicas, logísticas y operativas tomen en cuenta el impacto al ambiente y adopten las medidas de prevención y mitigación.

Por otro lado, la investigación científica no solo que crea conocimiento, sino que a la vez se constituye en un instrumento que apoya a la enseñanza universitaria en los campos de las ciencias de la vida, sociales, económicas, físicas, entre otras y al mismo tiempo apoya la existencia y expansión de los recursos humanos necesarios para desarrollar una plataforma tecnológica en donde se junten el sector académico, el gobierno y las organizaciones productivas para compartir recursos en la creación de un ambiente en donde se desarrolle un sistema económico competitivo con responsabilidad social y ambiental, con alto grado de innovación y creatividadl con el objetivo de generar productos, bienes, servicios e ideas que permitan alcanzar el buen vivir de la población.

En este contexto, se creó el Instituto Antártico Ecuatoriano en abril/04 como una entidad del gobierno dependiente del Ministerio de Defensa Nacional en reemplazo del Programa Antártico Ecuatoriano, dependiente del Instituto Oceanográfico de la Armada desde 1988. El flamante Instituto realiza labores de facilitador y coordinador del trabajo que hacen entidades de gobierno, universidades e instituciones privadas y que se orienta a alcanzar los cinco objetivos estratégicos antárticos en el marco de la política nacional adoptada por el Ecuador para asuntos antárticos.

A continuación se analizan los hechos relevantes relacionados al proceso, las opciones estratégicas disponibles, la implementación y consolidación del curso de acción estratégico adoptado como decisión para alcanzar los objetivos planteados en el marco de la política nacional para la Antártida, tratando de mantener al Instituto tan pequeño como sea posible, pero en cambio ganando terreno con el involucramiento de los diferentes sectores nacionales de carácter gubernamental, académicos y privados, la única forma como el país puede atender de una forma efectiva y eficaz los asuntos antárticos.

\section{2.- Materiales y Métodos:}

Hechos relevantes.

Aunque la Asamblea Nacional de 1967 declaró el interés nacional sobre la Antártida, se necesitaron 20 años para organizar la Primera Expedición Científica del Ecuador a la Antártida bajo la responsabilidad del Instituto Oceanográfico, una entidad de prestigio de la Fuerza Naval del Ecuador con la responsabilidad de llevar a cabo los levantamientos hidrográficos para la carta náutica nacional, investigación oceanográfica y de mantenimiento de las ayudas a la navegación en la costa y en la región insular(Galápagos); así, la expedición se hizo a bordo del $\mathrm{B} / \mathrm{I}$ ORION, un buque de investigación hidrográfica $\mathrm{y}$ oceanográfica construido para el Instituto en un astillero del Japón en 1982 y alistado para la expedición hacia los mares australes y la Península Antártica, por lo que la mayor parte de los científicos y tripulación pertenecían al propio Instituto y de hecho, la actividad científica se enfocó a la oceanografía del Paso Drake y del Estrecho Bransfield, empleando sistemas de posicionamiento satelital y ecosondas de última tecnología se hicieron algunos levantamientos hidrográficos expeditos que llevaron a la conclusión de que las cartas náuticas disponibles para la Península no eran seguras porque presentaban errores en posición y en profundidad, particular que es una permanente preocupación de la Organización Hidrográfica Internacional.

La Segunda Expedición Científica del Ecuador a la Antártida se realizó en el mismo ORION en el verano austral de 1990 con el objetivo de construir el primer modulo de la Estación Científica Maldonado en el lugar recomendado por la Primera Expedición (Moreano, 1990): Punta Fort William, Isla Greenwich, Shetland del Sur y el de ejecutar 20 proyectos de investigación en los alrededores de la Estación y en la Bahía Discovery ubicada al lado oriental de la Punta.

En la medida en la que Ecuador ganaba experiencia en la actividad antártica era necesario crear una estructura que le proporcione sustentabilidad, de manera que se propuso la política nacional (Moreano, 1992) y nació por un lado el Programa Antártico Ecuatoriano, dependiente del Instituto Oceanográfico y por otro La Comisión Sectorial de Investigación de la Antártida, dependiente del Consejo Nacional de Ciencia y Tecnología, como responsable de la ciencia y cuyos miembros pertenecían a diferentes instituciones académicas. Ambos organismos iniciaron su trabajo en forma coordinada a mediados de 1988 lo que les permitió preparar las posteriores expediciones. Con esta estructura y con dos expediciones ejecutadas con éxito, el Ecuador accedió a Miembro Consultivo del Tratado el 19 de noviembre de 1990 y como Miembro Pleno del Comité Científico sobre Investigación Antártica (SCAR por sus siglas en inglés) el 15 de junio de 1992.

En el período 1991 - 2004 se realizaron siete expediciones, de las cuales en solo una se empleó el R/V ORION y esto sucedió cuando se terminó la construcción del segundo módulo de la Estación Maldonado en 1998, las otras se realizaron empleando buques y aviones de países como Chile, Uruguay y Brasil. La mayor parte de los proyectos de investigación se enfocaron al área costera 


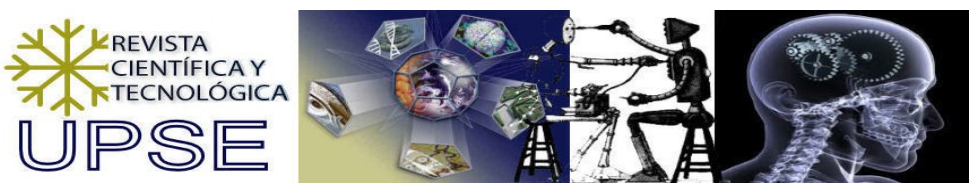

de Fort William con el apoyo de las facilidades de la Estación; sin embargo, la estructura científica sufría los impactos del debilitamiento del Consejo Nacional de Ciencia y Tecnología, por lo que la mayor parte de los proyectos los ejecutaron científicos pertenecientes al Instituto Oceanográfico, con una participación reducida del sector académico.

La Antártida es un continente muy complejo y exige que las instituciones nacionales se involucren en los temas científicos y logísticos, por lo que el Gobierno en cumplimiento al mandato del Congreso de 1987 creó el Instituto Antártico Ecuatoriano (INAE) en abril de 2004 como una entidad adscrita al Ministerio de Defensa Nacional y con su propio estatuto con:

La visión de ser reconocido en el contexto nacional e internacional como el Instituto líder en el tratamiento de los asuntos antárticos y

La misión de fomentar y mantener la proyección geopolítica del país y la participación permanente en las actividades de investigación científica en el contexto del Sistema del Tratado Antártico.

Los objetivos se resumen en:

1. Promover la participación activa del Ecuador en la Antártida para fines de investigación científica, con base en los intereses nacionales.

2. Contribuir con los esfuerzos de los Miembros del Tratado Antártico para la preservación del medio ambiente antártico.

3. Ejercer una presencia activa en los foros internacionales, relacionados con asuntos antárticos en colaboración con organismos públicos y privados del país.

4. Fomentar el intercambio de conocimientos técnico-científico con instituciones similares de los países Miembros del Tratado Antártico.

5. Armonizar las políticas nacionales que tengan relación con otros organismos y convenios internacionales.

Los fondos públicos para la operación del Instituto se incluyen cada año en el Presupuesto General del Estado.

Opciones Estratégicas:

Para la consecución de los objetivo, se plantearon tres Cursos de Acción

Estratégicos:

1. El Instituto mantiene el Statu Quo, es decir, continúa bajo el amparo del Instituto Oceanográfico, lo que implicaba permanecer en el pasado y crear serias dificultades para las tareas de facilitación y coordinación con el sector académico a fin de estructurar el grupo científico responsable de la actividad científica del Ecuador en el continente dedicado a la ciencia y a la paz.

2. El Instituto crece por si mismo, Implica la inclusión de personal científico, operativo y administrativo y la consecuente infraestructura, con la dificultad de que el Estado no asigna un presupuesto suficiente para implementar esta opción, lo que hace imposible atender todos los campos de la ciencia y se alarga el tiempo para la consecución de objetivos.

3. El Instituto crece a través de alianzas. Con el sector académico en lo científico y con la Fuerza Naval del Ecuador en lo operativo y logístico, lo que viabiliza la participación y cooperación, a mas de que se abarca más campos científicos, los investigadores son de cuarto nivel, es factible trabajar con el presupuesto anual disponible y se reduce el tiempo para la consecución de objetivos.

Es evidente que la opción 3. representa el mejor Curso de Acción Estratégico porque cumple con la misión, se ejecuta con los recursos disponibles, su relación: costo beneficio es superior y permite alcanzar los objetivos señalados, por lo que se la adoptó como decisión.

\section{Implementación Estratégica del Curso de Acción.}

El Instituto inició su trabajo con solo cinco personas: el Director Ejecutivo, el Jefe Financiero, la Asistente Científica, la Pagadora y la Asistente Contable, Se alquiló una oficina de 200 metros cuadrados en el Citibank ubicado en la Av. 9 de Octubre y Chile en Guayaquil y antes de que finalice el año 2005 se pusieron en orden los activos y los asuntos legales, pero al mismo tiempo se organizó la X Expedición integrada por expertos de la Fuerza Naval para que procedan con la reparación de los daños que presentaba la Estación Maldonado.

Como la Comisión Sectorial de Investigación de la Antártida había desaparecido como consecuencia de una serie de hechos que no ameritan ser discutidos, la tarea principal era organizar los cuadros de científicos en las diferentes disciplinas para conformar el Grupo Asesor Científico, para lo cual se hicieron contactos con docentes investigadores de diferentes universidades públicas $\mathrm{y}$ privadas con títulos de cuarto nivel entre los que se incluían también aquellos del Instituto Oceanográfico que aún mantenían interés en la investigación antártica, por lo tanto, la estrategia de organizar nuevamente el grupo asesor científico nacional se basó en construir una base sólida de científicos para luego obtener la autorización y apoyo de los Decanos y Rectores, quienes emitían la luz verde para su participación en los proyectos preparados por cada uno de ellos..

Aunque el proceso fue muy lento, terminó con éxito, ya que mucho antes de que finalice el año 2006 el grupo había sido conformado justo a tiempo para participar en el II Simposio Latinoamericano sobre Investigaciones en la 


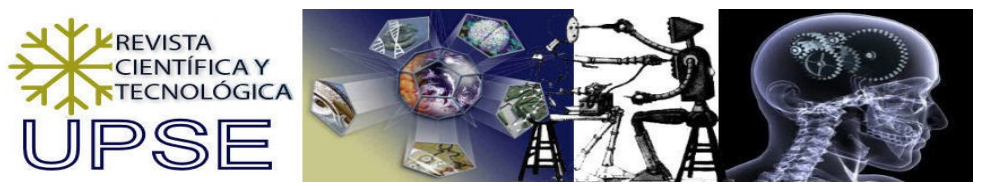

Antártida organizado por el Instituto Antártico Chileno y la Universidad de Concepción en Concepción - Chile en septiembre de 2006 y en donde el grupo asesor científico tuvo la oportunidad de interactuar con sus similares de Chile, Argentina, Brasil, Uruguay, Perú y Malasia. El grupo además, se actualizó en la situación de la ciencia antártica y especialmente en los proyectos de interés regional e internacional y también con el rol de la Universidad en la investigación de la Antártida.

La Secretaría Nacional de Ciencia y Tecnología reasumió sus funciones desde el año 2005 como el brazo operativo del Consejo Nacional de Ciencia y Tecnología, por lo que disponía de recursos para financiar proyectos de investigación, de manera que, el siguiente paso de la estrategia fue golpear sus puertas para buscar posibilidades de cooperación y aunque la Secretaría aceptó la iniciativa no se pudo concretar debido a problemas presupuestarios, pero de todas maneras la puerta estaba abierta para la cooperación mutua en el futuro cercano.

La estructura nacional para la ciencia antártica tomaba nuevamente forma con la participación de por lo menos 15 profesionales de diferentes universidades, con título de cuarto nivel que cooperaban con sus similares en proyectos regionales e internacionales, de manera que la implementación de la estrategia adoptada daba sus primeros resultados hacia la consecución de los objetivos estratégicos.

\section{3.- Resultados}

Consolidación Estratégica.

La mayor parte de los proyectos de los períodos 20062007 y 2007-2008 se realizaron en el área libre de hielo y nieve de la Estación Maldonado y en su mayoría se relacionaron a geología, glaciología, evolución del paisaje, levantamiento topográfico de Fort William, censo del petrel gigante del sur, lo que permitió presentar un reporte a SCAR sobre la situación de estas aves en el sector de la Estación Maldonado y cooperar así con el Acuerdo de Conservación de Albatros y Petreles (ACAP) que es un esfuerzo internacional para proteger a ambas especies de la amenaza de las pesquerías, trabajo dirigido por Friedman Kostner, ex Director de la Estación Científica Charles Darwin de Galápagos y ex Director de la Estación Científica de la Pontificia Universidad Católica del Ecuador en el Parque Nacional Yasuní.

La Zona Antártica Especialmente Administrada (ZAEA No 1) de la Bahía del Almirantazgo en la Isla Rey Jorge, Shetland del Sur, se creó mediante una medida adoptada por consenso durante la XXIX Reunión Consultiva del Tratado Antártico en junio de 2006, por lo que Brasil como promotor de la misma, asumió la coordinación de la gestión ambiental de la zona con la participación de: Ecuador, Estados Unidos, Perú y Polonia. Estos países mantienen estaciones y refugios en la Bahía y es lógico que se involucren en el Plan de Gestión de la ZAEA No. 1 a fin de reducir y mitigar los impactos de las actividades humanas. De esta forma el Ecuador se involucraba en un proyecto internacional y multidisciplinario en el marco del Protocolo de Madrid cuyo fin es la protección del medio ambiente antártico.

Por otro lado el grupo de especialistas ambientales actualizó el Plan de Manejo de la Estación Maldonado. El Plan incluye un conjunto de 12 planes integrados que tienen el objetivo de proteger la integridad física de las personas, de la infraestructura de la Estación y del ambiente de Fort William. El medico de la expedición actualizó el Manual de Primeros Auxilios para Zonas Polares, cuya primera edición se preparó en 1990.

La Fuerza de Tarea Antártica de Malasia y su contraparte ecuatoriana desarrollaron nuevas áreas de investigación en la biodiversidad de bacterias y hongos, así como en la fijación de nitrógeno por microbios, para lo cual se tomaron muestras a lo largo y ancho de Fort William. Los análisis de laboratorio demostraron resultados interesantes y los mismos se han presentado en seminarios, talleres y conferencias o se han publicado en revistas científicas especializadas.

La Isla Barrientos que pertenece al grupo de las islas Aitchio se ubica al norte de la Estación Maldonado y es uno de los 10 sitios más visitados por turistas en la Península y como el turismo es una actividad que crece rápidamente, se preparó un proyecto para evaluar el impacto de los visitantes en la fauna, flora y paisaje de la isla y estuvo a cargo del Dr. Gunther Reck ex Director de la Estación Científica Charles Darwin, que trabaja para la Universidad San Francisco de Quito y es consultor del Parque Nacional Galápagos en el tema de turismo, por lo tanto las "buenas prácticas" de Galápagos pueden ser adoptadas en Barrientos y en general a las guías de visita preparadas para cada sitio en donde se permite el desembarco de turistas. La experiencia se compartió durante la sesión: Gente y Recursos en los Polos en la Conferencia Abierta de Ciencia Polar organizada por el SCAR en San Petersburgo, Rusia en julio/08, a la que asistieron 4 miembros del grupo asesor científico luego de un riguroso proceso de selección a cargo de los organizadores.

El trabajo de campo en la Estación Maldonado consolidó la amistad entre los investigadores y el personal logístico y todos en conjunto lograron alcanzar los objetivos de la expedición y de cada uno de los proyectos de investigación científica. ( Detalles en el Anexo "la Actividad Científica Ecuatoriana en la Antártida")

La estrategia se consolidó con el Primer Simposio Ecuatoriano de Ciencia Polar que se organizó en forma conjunta por la Universidad Estatal Península de Santa Elena y el Instituto Antártico Ecuatoriano el 30 y 31 de julio/08. El evento científico fue precedido por una serie de charlas de especialistas en temas polares con la 


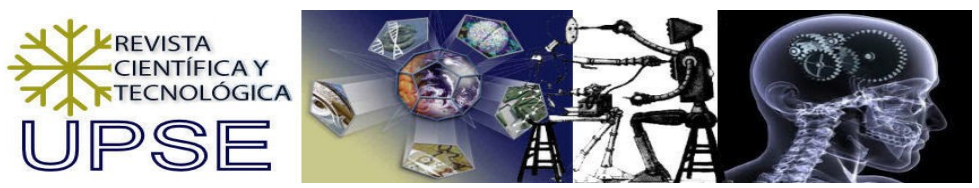

comunidad costera de la Península y posterior al evento se organizó el taller de bacterias y hongos en ambientes polares en los laboratorios de biología marina de la Facultad de Ingeniería Marítima y Ciencias del Mar de la Escuela Superior Politécnica del Litoral. Los tres eventos tuvieron un éxito más allá de lo esperado con la asistencia de 1240 personas entre investigadores, profesores, estudiantes y residentes locales.

Miembros de la Universidad Naval, de la Universidad Estatal Península de Santa Elena y del propio Instituto Antártico invitaron a la comunidad científica regional al V Simposio Latinoamericano Sobre Investigaciones Antárticas y al II Simposio Nacional de Ciencia Polar que se realizó en Salinas entre el 2 y 4 de septiembre de 2009.

La Cancillería incluyó el tema de la Antártida en el capítulo Guias Estratégicas en el Plan Nacional de Política Internacional (PLANEX 2007 - 2020) y la Asamblea Nacional Constituyente hizo lo propio en el párrafo cuarto del Art. 4 de la nueva Constitución de la República del Ecuador vigente que textualmente expresa: "El Estado Ecuatoriano ejercerá derechos sobre los segmentos correspondientes de la órbita sincrónica geoestacionaria, los espacios marítimos y la Antártida". Por su parte la SENPLADES incluye a la Antártida en la política 5.2c del objetivo 5 del Plan Nacional para el Buen Vivir 2009 - 20013.

\section{4.- Comentarios:}

Se dice y con buenas razones que las organizaciones tienen éxito o fracasan por causa de la calidad de las ideas y por la velocidad con la cual se las pone en práctica y que un buen lugar para buscarlas e implementarlas es la Universidad de docencia e investigación, en donde los activos más importantes son los profesores, estudiantes y el conocimiento que comparten (Andrew y Sirkin, 2003). Las Universidades son lugares en donde ocurre un intenso intercambio de ideas y en donde el trabajo se realiza en un ambiente descentralizado pleno de iniciativa, creatividad e innovación.

El Instituto siguió el camino de la universidad de docencia e investigación para conformar el grupo asesor científico con la inclusión de investigadores-profesores de cuarto nivel y de estudiantes interesados en la ciencia antártica para que conduzcan un trabajo de excelencia a pesar de las dificultades para financiar proyectos, pero el Instituto hizo una gestión exitosa en conseguir el financiamiento tanto para los proyectos como para su participación en talleres y simposios en donde tenían la oportunidad de presentar sus trabajos, interactuar con sus colegas y coordinar proyectos regionales o internacionales, lo que permitió que la estructura del grupo sea más sólida, que se creen las redes de conocimiento y que el Ecuador alcance mayor protagonismo en la ciencia antártica.

\section{5.- Conclusiones:}

El curso de acción estratégico adoptado como decisión mostró ser adecuado porque se cumplió con la misión, flexible porque se pudo ejecutarlo con los recursos disponibles y aceptable porque sus beneficios de concretar los objetivos propuestos superaron en mucho a la inversión.

La diversidad de los integrantes del grupo científico permitió enfocar la actividad de investigación desde diferentes campos de la ciencia y de la gestión ambiental, concretándose en la publicación de trabajos en medios especializados.

La coparticipación de la Fuerza Naval del Ecuador y en particular del Instituto Oceanográfico en lo operativo, logístico y científico fue decisivo para el éxito alcanzado.

El hecho de que el Instituto Antártico sea adscrito al Ministerio de Defensa Nacional no impidió en lo absoluto la consolidación del proceso con la participación de la Universidad de docencia e investigación.

El involucramiento de la Universidad Estatal Península de Santa Elena en la organización del Simposio Internacional aseguró la sostenibilidad del mismo y lo propio puede manifestarse del evento nacional.

\section{6.- Agradecimiento:}

El autor expresa su profundo agradecimiento a Hernán Moreano Jr. y Mónica Riofrío por sus oportunos comentarios y sugerencias.

\section{7.- Referencias:}

Andrew J. y Sirkin H. (2003). Innovating for Cash, Harvard Business Review 81(9). 76 - 85.

Moreano, H. (1990). Selección de sitio para la Estación Científica. Acta Antartica Ecatoriana. 1. 25-30.

Moreano H. (1992). Propuesta de la Política Nacional del Ecuador para la Antártida. Geopolítica Sudamericana 1, $22-25$.

Solven, O., Linqvist G. y Ketels C. (2003). The Cluster Initiative Greenbook,

Gutenberg, Suecia. 


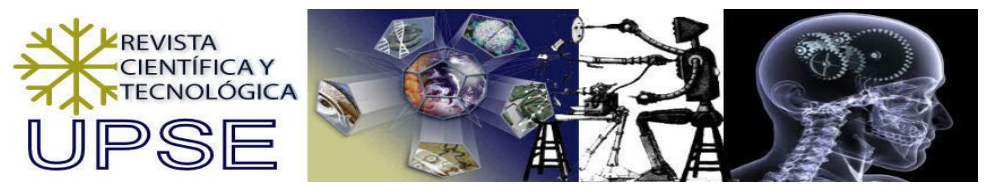

\section{LA ACTIVIDAD CIENTÍFICA ECUATORIANA EN LAANTÁRTIDA}

\section{5-2008}

Los proyectos de investigación desarrollados en la Antártida por el Ecuador estuvieron relacionados con los cinco grandes programas de investigación propuestas por el Comité Científico de Investigación Antártica (SCAR, por sus siglas en inglés) de esta manera el Ecuador, miembro pleno al igual que más de 34 países, participaría de programas científicos internacionales, innovativos y de alta calidad que atiendan a temas clave de importancia global. En estos programas se procuró impulsar aquellos temas que tuvieran sus conecciones con el Ecuador.

Los cinco programas mencionados son:

1. Exploración de los Lagos Subglaciales

2. La Antártida y el Sistema del Clima Global

3. Evolución del Clima Antártico

4. Evolución y Diversidad en la Antártida

5. Efectos de la Conjugación Inter-hemisférica en la Investigación solar, terrestre y Agronómicas.

En el programa 1 y 5, el Ecuador no desarrolló proyectos de investigación.

\section{PROGRAMAS Y PROYECTOS EJECUTADOS EN LA ANTÁRTIDA}

\begin{tabular}{|c|c|c|c|c|}
\hline NO. & PROYECTO Y PARTICIPANTES & $\begin{array}{c}\text { PAÍSES } \\
\text { COOPERANTES } \\
\end{array}$ & $\begin{array}{c}\text { AÑOS DE } \\
\text { EJECUCIÓN }\end{array}$ & $\begin{array}{l}\text { INSTITUCIONES } \\
\text { PARTICIPANTES }\end{array}$ \\
\hline \multicolumn{5}{|c|}{$\begin{array}{l}\text { PROGRAMA: Evolution of the landscape in response to tectonic, sea-level and glacial retreat in North Antarctic } \\
\text { Península }\end{array}$} \\
\hline 1 & $\begin{array}{l}\text { Detailed high-resolution mapping of the } \\
\text { raised beaches in Greenwich Island. Rosdi } \\
\& \text { Burbano. }\end{array}$ & Ecuador y Malasia & $\begin{array}{l}\text { 2007-2008 y } 2009 \\
\text { (concluido) }\end{array}$ & $\begin{array}{l}\text { Instituto } \\
\text { Oceanográfico de la } \\
\text { Armada (INOCAR), }\end{array}$ \\
\hline 2 & $\begin{array}{l}\text { Detailed spatial mapping of geological } \\
\text { features and floral distributios and landuse } \\
\text { by the different fauna. Rosmadi \& Salazar. }\end{array}$ & & & $\begin{array}{l}\text { Universidad Estatal } \\
\text { Península de Santa } \\
\text { Elena (UPSE), Escuela }\end{array}$ \\
\hline 3 & $\begin{array}{l}\text { Sedimentology of lakes with the aim of } \\
\text { characteristing the physical characteristics, } \\
\text { sediment-type, morphological evolution } \\
\text { and sedimentation history of these lakes as } \\
\text { a record of glacial retreat. Hussin, Dumont } \\
\text { \& Santana. }\end{array}$ & & & $\begin{array}{l}\text { Superior Politécnica } \\
\text { del Litoral (ESPOL). } \\
\text { University of Malaya } \\
\text { and University of } \\
\text { Technology Mara }\end{array}$ \\
\hline \multicolumn{5}{|c|}{$\begin{array}{l}\text { PROGRAMA: Microbial Diversities around Maldonado Station, Antarctica: Distribution, Abundante and } \\
\text { Physiology of selected fungi, algae, bacteria and cyanobateria. }\end{array}$} \\
\hline 4 & $\begin{array}{l}\text { Biodiversity and bioactivity of Antarctic } \\
\text { fungi. Aysah, Omar, Cárdenas \& Ordóñez }\end{array}$ & Ecuador y Malasia & $\begin{array}{l}2007-2008 \text { y } 2009 \\
\text { (en ejecución) }\end{array}$ & $\begin{array}{l}\text { ESPOL, Universidad } \\
\text { San Francisco de Quito } \\
\text { (USFQ), National }\end{array}$ \\
\hline 5 & $\begin{array}{l}\text { Biodiversity of Antarctic micro-algae. } \\
\text { Siew \& Weng }\end{array}$ & & & $\begin{array}{l}\text { Center of Atmospheric } \\
\text { Research (NCAR- } \\
\text { INAE), Universiti }\end{array}$ \\
\hline 6 & $\begin{array}{l}\text { Biodiversity and Bioactivity of bacteria. } \\
\text { Wong, Yoke \& Guerra }\end{array}$ & & & $\begin{array}{l}\text { Malaya, Univerity of } \\
\text { Malaya, Universiti }\end{array}$ \\
\hline
\end{tabular}



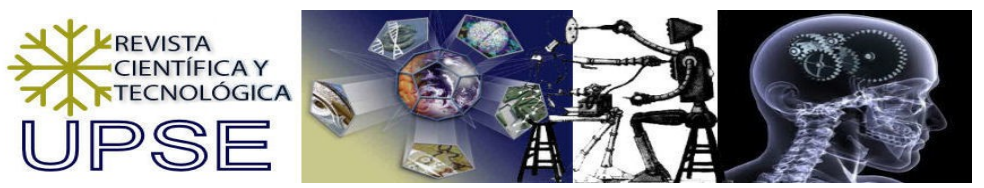

\begin{tabular}{|c|c|c|c|c|}
\hline 7 & $\begin{array}{l}\text { Profiling hidrocarbons and nutrient } \\
\text { deposition vertical transport and } \\
\text { mobilization in Antarctica: M. Zacaria, P. } \\
\text { Calle, H. Yii \& M. Borbor }\end{array}$ & & & $\begin{array}{l}\text { Malaysia Sabah, } \\
\text { Universiti Putra } \\
\text { Malaysia, Universiti } \\
\text { Malaysia Terengganu. }\end{array}$ \\
\hline \multicolumn{5}{|c|}{ Programa: Antarctic Climate Evolution } \\
\hline 8 & Geodesia y Glaciología & Ecuador & 2007-2008-2009 & INOCAR \\
\hline 9 & $\begin{array}{l}\text { Estudio de la evolución multitemporal de } \\
\text { los glaciares de la Isla Greemwich- } \\
\text { Antártida } \\
\text { Componentes: } \\
\text { a. Determinación de la dinámica espacial } \\
\text { de los glaciares de la Isla Greenwich. } \\
\text { Burbano \& Gutiérrez } \\
\text { b. Determinación de caudales de deshielos } \\
\text { de vertientes del glaciar Quito. Ycaza \& } \\
\text { Borbor }\end{array}$ & Ecuador & $2007-2008-2009$ & $\begin{array}{l}\text { Centro Nacional de } \\
\text { Recursos Hídricos } \\
\text { (CNRH), } \\
\text { Instituto Nacional de } \\
\text { Metereología e } \\
\text { Hidrología (INAMHI), } \\
\text { NCAR-INAE, } \\
\text { INOCAR }\end{array}$ \\
\hline 10 & $\begin{array}{l}\text { Análisis de las morfologías litorales para } \\
\text { identificar variaciones climáticas durante } \\
\text { el holoceno superior. Santana, Dumont \& } \\
\text { Hussin }\end{array}$ & Ecuador y Malasia & 2008 y 2009 & $\begin{array}{l}\text { INOCAR, ESPOL y } \\
\text { University of Malaya }\end{array}$ \\
\hline 11 & $\begin{array}{l}\text { Estudio de las comunidades marinas } \\
\text { Bentónicas (Intermareal) en Bahía } \\
\text { Guayaquil (Bahía Chacón) e Isla } \\
\text { Barrientos. Estrecho Inglés, Islas } \\
\text { Shetland. Torres, Cárdenas, Calderón, } \\
\text { Cornejo, Guerra, Mero, Palacios y Arcos }\end{array}$ & Ecuador & 2007,2008 у 2009 & $\begin{array}{l}\text { INOCAR, Universidad } \\
\text { Estatal de Guayaquil, } \\
\text { USFQ y ESPOL }\end{array}$ \\
\hline 12 & $\begin{array}{l}\text { Censo del petrel gigante del sur } \\
\text { (Macronectes giganteus) y programa de } \\
\text { anillamiento. F. Koester \& P.Piedrahita }\end{array}$ & $\begin{array}{l}\text { Ecuador y Estados } \\
\text { Unidos }\end{array}$ & 2007 y 2008 & $\begin{array}{l}\text { Pontificia Universidad } \\
\text { Católica del Ecuador } \\
\text { (PUCE) }\end{array}$ \\
\hline 13 & $\begin{array}{l}\text { Cobertura Vegetal en los alrededores de la } \\
\text { Estación Maldonado. Yii, Borbor y } \\
\text { Ordóñez }\end{array}$ & Ecuador y Malasia & 2008 y 2009 & $\begin{array}{l}\text { Universiti Malaysia } \\
\text { Terengganu., NCAR- } \\
\text { INAE y ESPOL }\end{array}$ \\
\hline 14 & $\begin{array}{l}\text { Plan de Gestión de la Zona Antártica } \\
\text { Especialmente Administrada (ZAEA No. } \\
\text { 1). Brito, Gagliuffi, Borbor \& Riofrío }\end{array}$ & $\begin{array}{l}\text { Brasil, Ecuador, } \\
\text { Estados Unidos, } \\
\text { Perú y Polonia }\end{array}$ & 2007,2008 у 2009 & $\begin{array}{l}\text { INAE, Programa } \\
\text { Antártico de Brasil, } \\
\text { Instituto Antártico del } \\
\text { Perú, Programa } \\
\text { Antártico de Polonia y } \\
\text { Programa Antártico de } \\
\text { Estados Unidos. }\end{array}$ \\
\hline 15 & $\begin{array}{l}\text { Plan de Manejo Ambiental en la Estación } \\
\text { Maldonado, Moreano, Chavarría, Guerra, } \\
\text { Palacios y Recalde }\end{array}$ & Ecuador & 2007,2008 & $\begin{array}{l}\text { INAE, UPSE, USFQ e } \\
\text { INOCAR }\end{array}$ \\
\hline 16 & $\begin{array}{l}\text { Turismo en Isla Barrientos. Reck \& } \\
\text { Proaño }\end{array}$ & Ecuador & 2007,2008 & USFQ \\
\hline
\end{tabular}




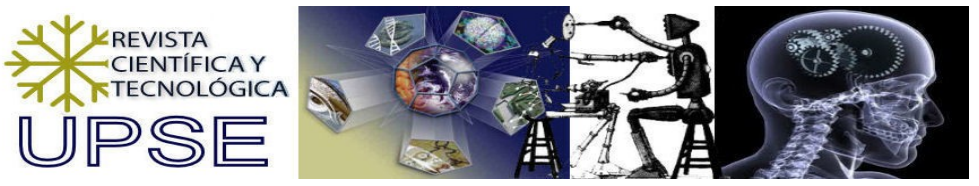

\section{PRODUCTOS OBTENIDOS A PARTIR DE LA EJECUCION DE LA ACTIVIDAD CIENTIFICA 2006-2008}

1.- Participación de científicos ecuatorianos, exponiendo sus resultados investigativos como autores o coautores en los siguientes foros nacionales e internacionales:

- I Simposio Ecuatoriano de Ciencia Polar, La Libertad, 2008: 1 conferencia Magistral (INAE); 16 Exposiciones Orales (INAMHI. ESPOL, UPSE, NCAR-INAE, Programa de Manejo Sustentable de Recursos Marino Costeros de la Costa Centro Sur de la Provincia de Esmeraldas, PUCE, ESPOL, Pacific Whale Foundation, FEMM, INOCAR, Universidad de Guayaquil); 4 exposiciones de Posters ( FEMM, UPSE, Escuela de los Chefs y Universidad de Guayaquil).

- RAPAL, Comité Científico: 2005, 2006, 2007, 2008.

- IV Simposio Latinoamericano sobre Investigaciones Antárticas, Valparaíso-Chile, 2008: 5 exposiciones orales (USFQ, UPSE, ESPOL, Escuela de los Chefs): 4 exposiciones de Posters (UPSE, ESPOL, PUCE).

- SCAR-ASCS IPY, Open Science Conference,, San Petersburgo-Rusia, 2008: 3 Investigadores ecuatorianos (Gunther Reck, Mercy Borbor, Hernán Moreano y Arturo Cadena) representantes de la USFQ, NCAR e INAE fueron invitados a participar como copresidentes de Sesiones Científicas: Polar Global Linkages (1), People and resources at the Poles (2) y Antarctic Tourism (3), 1 Exposición Oral ( NCAR-INAE) y 1 Exposición Poster ( ESPOL).

- X ISAES (Internacional Simposyum on Antarctic Earth), Santa Bárbara-USA, 2007: 1 Exposición Oral ( NCAR-INAE); 1 Presentación de Poster (INOCAR) 

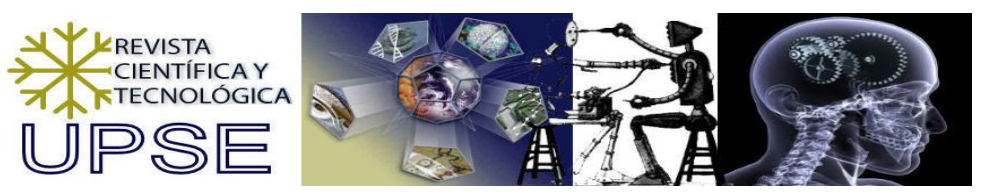

- III Simposio Latinoamericano sobre Investigaciones Antárticas, Buenos AiresArgentina, 2007: 3 exposiciones orales (USFQ, UPSE, ESPOL): 4 exposiciones de Posters (UPSE, USFQ, NCAR, INAE).

- II Simposio Latinoamericano sobre Investigaciones Antárticas, Concepción-Chile, 2006: 4 exposiciones orales (INOCAR): 2 exposiciones de Posters (INOCAR).

\section{2.- Publicaciones de los resultados de las Investigaciones en Revistas Científicas y de divulgación}

\begin{tabular}{|c|c|}
\hline Revista & Artículos científicos publicados \\
\hline $\begin{array}{l}\text { Libro de Resúmenes- II } \\
\text { Simposio Latinoamericano } \\
\text { sobre Investigaciones } \\
\text { Antárticas y VI Reunión } \\
\text { Chilena de Investigación } \\
\text { Antártica, INACH-Punta } \\
\text { Arenas-Chile, } 2006 .\end{array}$ & $\begin{array}{l}\text { 1) Incidencia del efluente residual doméstico proveniente de la estación } \\
\text { científica Pedro Vicente Maldonado en la calidad de agua de la ensenada } \\
\text { Guayaquil. Palacios, C. } \\
\text { 2) Unidad de tratamiento para aguas residuales domésticas en la estación } \\
\text { científica Pedro Vicente Maldonado. Palacios, C. } \\
\text { 3) Secuencia de cordones litorales clásticos en Punta Fort William, Isla } \\
\text { Greenwich, Península Antártica. Santana, E. y Dumont, J.F. } \\
\text { 4) Nota preliminar sobre algas de nieve "snow algae" en Punta Fort } \\
\text { William (Isla Greenwich-Antártida), Enero 2004. Torres, G. y Palacios, } \\
\text { C. } \\
\text { 5) Sitios de anidación de macronectes giganteus y catharacta lonnbergi } \\
\text { en Punta Fort William ( 2004), en Isla Greenwich-Shetland del Sur- } \\
\text { Antártida. Torres, G. } \\
\text { 6) Descripción de la comunidad bentónica litoral de Fort William en Isla } \\
\text { Greenwich-Antártida, Enero-Febrero 2004. Torres, G. y Calderón, T. } \\
\text { 7) Interacción del fitoplancton-zooplancton y sus condiciones } \\
\text { oceanográficas en Isla Greenwich - Antártida, durante el verano austral } \\
\text { 2004. Torres G., Palacios, C., Calderón T. y Recalde S. }\end{array}$ \\
\hline $\begin{array}{l}\text { Revista Tecnológica, ESPOL: } \\
\text { Vol. 19, No.1, 2006; Vol. 20, } \\
\text { No. 1, 2007 y Vol. 21, No. 1, } \\
\text { Guayaquil-Ecuador, } 2008 .\end{array}$ & $\begin{array}{l}\text { 1) Interacción del fitoplancton-zooplancton y sus condiciones } \\
\text { oceanográficas durante el verano austral } 2004 \text { (Isla Greenwich- } \\
\text { Antártida). Torres G., Palacios, C., Calderón T. y Recalde S. } \\
\text { 2) Características granulométricas de los cordones litorales en Punta Fort } \\
\text { William, Isla Greenwich, Península Antártica. Santana, E. y Dumont, J.F. } \\
\text { 3) Nota preliminar sobre algas de nieve "snow algae" en Punta Fort } \\
\text { William (Isla Greenwich-Antártida), Enero 2004. Torres, G. y Palacios, } \\
\text { C. } \\
\text { 4) Tratamiento de aguas residuales domésticas en la estación científica } \\
\text { Pedro Vicente Maldonado-Antártida, verano austral 2003-2004. Palacios, } \\
\text { C. }\end{array}$ \\
\hline
\end{tabular}




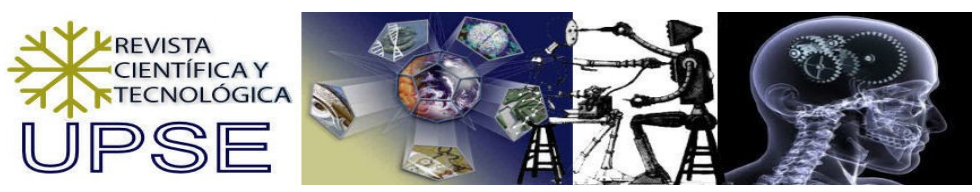

\begin{tabular}{|c|c|}
\hline & $\begin{array}{l}\text { 5) Censos del petrel gigante del sur macronectes giganteus y las skúas } \\
\text { catharacta spp. en la Punta Fort William-Isla Greenwich y la Isla } \\
\text { Barrientos, Shetland del Sur-Antártida. Koester, F. y Piedrahita P. } \\
\text { 6) Estudio preliminar de la cobertura superficial en la Isla Greenwich, } \\
\text { Antártida. Ordóñez, N., Yii. H, et al }\end{array}$ \\
\hline $\begin{array}{l}\text { Ecuador Antártico, INAE, No. } \\
\text { 3, } 2007 \text { y No. 4, Guayaquil- } \\
\text { Ecuador, } 2008 \text {. }\end{array}$ & $\begin{array}{l}\text { Geología, glaciología y evolución del paisaje del norte de la Isla } \\
\text { Greenwich del grupo de las Shetland del Sur en la Península Antártica. } \\
\text { Hussin, A.y Santana, E. } \\
\text { Monitoreo de Glaciares, Isla Greenwich -Antártida. Ycaza, P. y } \\
\text { Burbano, L. } \\
\text { Distribución del fitoplancton marino costero y del macrobentos } \\
\text { intermareal adyacente a Punta Fort William durante el verano austral, Isla } \\
\text { Greenwich-Antártida. Torres, G. , Calderón T., Palacios, C. y Cornejo, } \\
\text { M. } \\
\text { Censo de petreles gigantes y skúas. Koester, F. y Piedrahita, P. } \\
\text { Estudio de la biodiversidad de hongos y bacterias y la fijación de } \\
\text { nitrógeno por microbios. Yoke Ch., et al } \\
\text { Gestión ambiental y monitoreo de la Bahía del Almirantazgo (ZAEA No. } \\
\text { 1), Isla Rey Jorge. Iniciando una colaboración internacional. Borbor, } \\
\text { M., et al } \\
\text { Tratamiento y eliminación de residuos en la Estación Maldonado. } \\
\text { Chavarría J., Guerra, M.L. y Moreano, H. } \\
\text { Turismo en Barrientos. Reck, G. y Proaño R. }\end{array}$ \\
\hline $\begin{array}{l}\text { Libro de Resúmenes- I } \\
\text { Simposio Ecuatoriano de } \\
\text { Ciencia Polar. INAE - } \\
\text { Guayaquil-Ecuador, } 2009 .\end{array}$ & $\begin{array}{c}\text { (En preparación: Se publicarán } 18 \text { artículos científicos ecuatorianos } \\
\text { presentados en el evento) }\end{array}$ \\
\hline $\begin{array}{l}\text { ASM Science Journal 3(2), } \\
\text { 2009. Academia de Ciencias de } \\
\text { Malasia. }\end{array}$ & $\begin{array}{l}\text { En preparación. Se han aceptado varios artículos presentados en forma } \\
\text { conjunta por científicos de universidades de Malasia y Ecuador. }\end{array}$ \\
\hline
\end{tabular}

\section{3.- Coparticipación del INAE en Proyectos de Investigación presentado a entidades de financiamiento}

Año 2008

- Programa CLIMANTAR: Centro de Investigaciones Aplicadas de la Variabilidady Cambio Climático en el Pacífico Suroriental y Antártida, y su influencia e impacto en la costa ecuatoriana.

Fue aprobado por la SENACYT con prioridad 4

Instituciones involucradas: UPSE, INAE, PUCESE, Ministerio de Ciencia y Tecnología de Brasil, CAML (Brasil), INACH (Chile), Programa Antártico Peruano y otras universidades nacionales. 

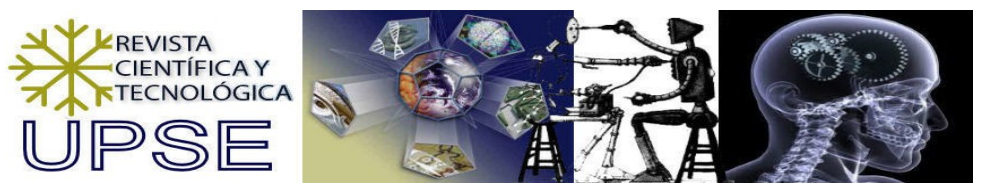

Año 2007

- Proyecto Semilla: UVIP: An Underwater Vehicle Investigation Prototype.

Fue aprobado, está actualmente en ejecución y está siendo financiado con fondos VLIR-ESPOL. Instituciones involucradas: ESPOL - INAE 